\title{
The Plasminogen Activator/Plasmin System
}

\author{
Jean-Dominique Vassalli, André-Pascal Sappino," and Dominique Belin* \\ Departments of Morphology, ${ }^{*}$ Medicine, and ${ }^{\ddagger}$ Pathology, University of Geneva Medical School, 1211 Geneva 4, Switzerland
}

Over the last 10 years, our knowledge of extracellular proteolysis has progressed dramatically. Different enzymatic cascades cooperate to achieve extracellular matrix $(\mathrm{ECM})^{1}$ degradation, and a number of participant proteins have been characterized and cloned. Physiological inhibitors have been identified for most of these enzymes. Also, the concept of focused proteolysis, through binding of enzymes and inhibitors to specific regions of the extracellular milieu, has received broad experimental support. Finally, the biosynthesis of many of the relevant proteases and inhibitors has been shown to be under the control of hormones and growth factors. Plasminogen activators (PAs) and their inhibitors (PAIs) are thought to be key participants in the balance of proteolytic and antiproteolytic activities that regulates matrix turnover. This article summarizes the evidence that supports this contention, discusses the role of PAspecific cell surface binding sites, and also draws attention to a number of instances in which the presence of PAs cannot be reconciled with an exclusive function in ECM degradation.

\section{The plasminogen activator/plasmin system}

\section{ENZYMES}

PAs are serine proteases of tryptic specificity. Two enzymes, differing mostly in the domain organization and function of their noncatalytic regions, have been identified in mammals: urokinase-type PA (uPA) and tissue-type PA (tPA) (1). They are the products of distinct genes, and are secreted as singlechain (sc) proteins; whereas sc tPA is active, sc uPA is essentially inactive (pro-uPA) (2). Cleavage of pro-uPA by plasmin, kallikrein, Factor XIIa or cathepsin B (3) yields the disulfidelinked two-chain active enzyme. The two PAs have distinct targeting determinants in their noncatalytic regions: the "growth factor domain" of uPA directs the binding of the enzyme (and that of pro-uPA) to a plasma membrane receptor (4, 5 ), whereas other structural domains in tPA (the "finger" region and the "kringles") allow its binding to fibrin and other

It is impossible to select a small set of references that would provide appropriate coverage of the entire field discussed. We have thus included references to reviews and to recent papers that can be used to trace back earlier work. We apologize to all our colleagues whose contributions are not adequately referenced, as well as to our readers. 1991

Received for publication 1 April 1991 and in revised form 28 May

1. Abbreviations used in this paper: ECM, extracellular matrix; PA, plasminogen activator; PAI, plasminogen activator inhibitor; sc, single chain; tc, two-chain; tPA, tissue-type PA; uPA, urokinase-type PA.

J. Clin. Invest.

(c) The American Society for Clinical Investigation, Inc.

$0021-9738 / 91 / 10 / 1067 / 06 \$ 2.00$

Volume 88, October 1991, 1067-1072 components of the ECM (6). These and perhaps additional interactions, for instance with heparinlike molecules, could have a dramatic effect on the focusing of PA-controlled proteolysis (7). The different extracellular addressing of the two PAs suggests that they play different biological roles.

Plasminogen is the prefered substrate for PAs, but other molecules may also be cleaved by one or the other PA; for instance, avian uPA exerts a plasmin-independent effect on the morphology of chick fibroblasts (8). Plasminogen is present in plasma and extracellular fluids at a 1-2 $\mu \mathrm{M}$ concentration, in the range of the $K_{\mathrm{m}}$ of the activation reaction. It can associate with fibrin and other proteins via lysine-binding sites located in the kringles of its noncatalytic portion (9). The PA-catalyzed cleavage of an Arg-Val bond yields the active enzyme plasmin, consisting of two polypeptide chains linked by a disulfide bond; Arg-esterases other than PAs can activate plasminogen, but only tPA and uPA appear to do so under physiological conditions. Like PAs, plasmin belongs to the serine protease family, and has tryptic specificity; by contrast to PAs, however, it has a very broad spectrum of substrates. Whereas the "classical" plasmin substrate is fibrin, in the context of ECM proteolysis it is clear that most other matrix proteins can also be cleaved by this enzyme. In addition, plasmin is one of the activators of metalloproteases precursors (10), and could thus play a pivotal role in ECM degradation; whether the PA-plasmin system controls matrix turnover is, however, debatable, because the ratelimiting step in such enzymatic cascades may vary from situation to situation, and need not be the most proximal. Plasmin has also been found to activate latent forms of certain growth factors (11), and its role should hence not be considered as limited to degradative events. PA-catalyzed activation of plasminogen results in a dramatic amplification of the proteolytic capacity of PA-producing cells, by recruitment of the vast reservoir of potential, broad spectrum proteolysis represented by plasminogen in the pericellular environment.

\section{INHIBITORS}

Four arginine-specific serine-protease inhibitors (Arg-serpins) are of particular relevance to the PA/plasmin system (12). Their preferred target enzyme(s), as determined by the kinetic constants of complex formation, are different.

Plasminogen activator inhibitor 1 (PAI-1) is the major PAI in plasma. It has high affinity for tPA, both sc and two-chain (tc), as well as for UPA. PAI-1 is secreted as an active antiprotease, but it rapidly converts to an inactive latent form, which can be reactivated by exposure to chaotropic agents or phospholipids; this latency is not shared by other serpins, and its molecular basis remains unexplained. PAI-1 is often found associated with plasma and ECM vitronectin, which stabilizes it in the active conformation (13). In addition, vitronectin and heparin affect the specificity of PAI-1, by enhancing its reactivity toward thrombin (14). 
Plasminogen activator inhibitor 2 (PAI-2) inhibits UPA and also, albeit less efficiently, tPA (tc but not sc). The rate constants of uPA and tPA inhibition are not as favorable as with PAI-1, and this raises the possibility that PAI-2 may control the activity of other, yet unidentified, enzymes. In this context it is intriguing that PAI-2, in addition to being a secreted protein, is also abundant in the cytosol of cells that synthesize it (15), whereas PAs are exclusively secretory proteins.

Protease-nexin I (PN-I) inhibits uPA, plasmin, and thrombin; its reactivity towards thrombin (but not towards the other two enzymes) is dramatically enhanced in the presence of heparin. The dual role of PN-I as an inhibitor of fibrin deposition and removal suggests that it may be designed to dampen multiple enzymatic pathways which, if active, would affect the metabolism of the extracellular milieu.

$\alpha 2$-antiplasmin is the primary plasmin inhibitor in plasma. Interestingly, if the lysine-binding sites of plasmin are occupied, inhibition by $\alpha 2$-antiplasmin is markedly reduced (16); this is thought to localize the activity of plasmin to specific regions of the extracellular environment, such as on fibrin or in the immediate vicinity of the cell surface.

\section{CELL SURFACE BINDING SITES}

A sharper image of the biological role of the PA/plasmin system has come from observations indicating that PAs and plasminogen can bind to cell surfaces.

$U P A$ receptor is present on the plasma membrane of a number of cell types $(4,5)$. It binds with similar kinetics uPA and pro-uPA, formerly considered as secreted proteins acting in solution in extracellular fluids. This receptor comprises at least one polypeptide chain, which is inserted in the plasma membrane through a glycerophospholipid anchor (17). Binding involves the "growth factor-like" domain of uPA, and receptorbound UPA remains functionally active at the cell surface with a half-life of 4-5 h (18). Recent studies $(18,19)$ demonstrate that receptor-bound UPA is not protected from inhibition by PAI-1 or PAI-2.

Different cellular binding sites for $t P A$ have been described. Some of these are clearly involved in the clearance (in particular by the liver) of the enzyme, or of tPA-PAI complexes (20), whereas others localize tPA to the plasma membrane, for instance on endothelial cells and neurons $(21,22)$; they are different from the characterized UPA receptor. Because tPA also binds to components of the ECM, positive identification of these cellular binding site(s) will be required to ascertain whether they are plasma membrane constituents.

Plasminogen and plasmin bind to different cell types, including cells that also express uPA receptors (9). Binding appears to be to proteins with an exposed carboxy-terminal lysine residue, and recent results identify a plasma membrane form of enolase as one major plasminogen receptor site (23). This and other observations suggest that the lysine-binding domains of plasminogen are involved.

\section{Cell biology of plasminogen activation}

REGULATION OF SYNTHESIS

The range of cell types that can produce one (or more) of the constituants of the PA/plasmin system is extremely broad, and includes derivatives from the three germ layers, cells from the male and female germ lines, as well as cells from extraembryonic tissues. In fact, it may be that, given the circumstances, all cell types can produce PAs and/or PAIs. PAs and PAI- 1 are present in blood plasma, and so is PAI-2 during late pregnancy. PAI-1 is also a major constituant of certain ECM. However, these proteins are by no means constitutive components of the extracellular milieu: expression of the PA/plasmin system is a highly dynamic aspect of the cellular phenotype.

A large body of work has explored the regulation of expression of PAs (1) and PAIs (12), in many different cell lineages. Most often, transcriptional mechanisms have been shown to play a determining role (24-26), although in at least one instance regulation is clearly posttranscriptional (27). The important concept to emerge from these studies is that probably all signal transduction pathways can affect the PA/plasmin system. Some pathways have similar effects in many different cell types: for instance glucocorticoids seem to uniformly decrease uPA transcription and mRNA levels, and often increase expression of the PAI- 1 gene. By contrast, a given pathway can have opposite effects depending on the cell type: CAMP and related agents can increase (26) or decrease (28) uPA gene transcription. In this context, the observation that the same nuclear factor can activate UPA and collagenase transcription provides a new example of cooperation between the plasmin and metalloprotease cascades (24). The intricate regulation of PA and PAI synthesis allows expression of the PA/plasmin system to be precisely controlled in time, in a manner that depends upon the endocrine or growth factor balance. One striking illustration of this is provided by the effect of bFGF and TGF $\beta$ on endothelial cells: both agents enhance PAI- 1 and UPA mRNA and protein synthesis, but the kinetics and amplitude of the changes in expression of the two genes are remarkably different, so that the overall balance is tilted towards enhanced proteolysis in response to bFGF, and towards antiproteolysis in response to TGF $\beta$ (29). This shift in the proteolytic balance of endothelial cells probably plays an important part in the TGF $\beta$-mediated antiangiogenic properties of cartilage $(30,31)$.

\section{SECRETION}

It is in general considered that PAs and PAIs follow the constitutive secretory pathway, i.e., that secretion rapidly follows synthesis (with the exception of the cytosolic form of PAI-2 [15]). However, immunohistochemical analysis of uPA in the mouse vas deferens suggests that the antigen is present in apical granules (32), and can therefore follow the pathway for regulated secretion. Also, in human PMNs expression of uPA activity at the cell surface can be triggered by exposure to secretagogues (33). Thus, regulation of enzyme or inhibitor secretion may represent yet another control point for expression of the PA/ plasmin system. One aspect that has not yet received appropriate attention is the possible polarization of PA and PAI secretion by epithelial cells (34). A systematic study of this issue may help elucidate the physiological role(s) of the PA/plasmin system in epithelial tissues. In addition, a perturbation of the polar release of PAs or PAIs could be detrimental to tissue architecture or function, and pathogenic; for instance the basolateral release of a PA normally destined for apical secretion may result in proteolytic damage to the underlying basement membrane and hence play a part in the acquisition of invasive properties by malignant epithelial cells.

\section{CELL SURFACE EXPRESSION: UPA RECEPTOR}

The biological consequences of plasminogen activation may differ as a function of the type of PA produced: for instance, uPA favors cell migration through the ECM, whereas catalyti- 
cally equivalent amounts of tPA are ineffective (35). This could result from the binding of each PA to different cell surface or ECM sites. The uPA receptor thus probably plays an important part in the spatial control of PA-catalyzed proteolysis.

Cell types expressing uPA receptors include monocytes/ macrophages, PMNs, fibroblasts, endothelial cells, keratinocytes. Expression of uPA receptors can be modulated, so that their number and affinity will vary under the influence of growth factors $(5,36)$. Immunochemical studies have demonstrated the presence of uPA, presumably receptor bound, at sites of attachment of fibroblasts to the substratum and its colocalization with the cytoskeletal component vinculin (37). Furthermore, there is a rapid redistribution of the uPA receptor to the leading edge of monocytes induced to migrate in response to a chemotactic gradient (18). Thus, expression of the uPA receptor can be a highly dynamic property of at least certain cell types.

The existence of plasma membrane binding sites for uPA, plasminogen, and plasmin points to the cell surface as the site of assemblage of a powerful proteolytic system. At least two steps in the PA/plasmin cascade are dramatically enhanced by this process: (a) activation of pro-uPA is markedly increased when it is receptor-bound and when plasminogen is simultaneously present on the cell surface, and this in turn accelerates plasmin formation (38); $(b)$ plasmin on the cell surface is protected from $\alpha 2$-antiplasmin in plasma and extracellular fluids (9). Taken together, these observations suggest how plasmin generation and activity can be focused to restricted domains of the cellular environment, such as the leading edge of migrating cells. Current views on the involvement of UPA in cell migration and invasion are illustrated in Fig. 1.

The source of uPA that binds to the receptor may differ for different cell types. In certain cases uPA is synthesized by receptor-bearing cells, and binds in an autocrine way after secretion (5). However, pro-uPA is present in blood plasma and could bind to receptor-bearing circulating cells. Similarly, mouse spermatozoa bind uPA secreted by epithelial cells of the vas deferens (39). In human colon adenocarcinomas, increased levels of uPA are produced by stromal cells, whereas uPA receptor mRNA is present in the malignant cells (40). The possibility of paracrine loading of UPA on receptor-bearing cells increases the versatility of this system, and could provide an example of cooperation between different cells in tissues.

The uPA receptor may also serve other functions. Membrane-bound uPA/PAI- 1 and uPA/PAI-2 complexes are rapidly cleared from the cell surface by endocytosis, suggesting that the receptor promotes their intracellular degradation $(5$, 18). Most interestingly, recent results indicate that uPA binding to its receptor can stimulate the differentiation or proliferation of myeloid and other cells (41). These observations suggest that the uPA receptor can also function in a signal transduction mode, and thus that uPA should perhaps be viewed as a bifunctional molecule with both growth factor and enzymatic activities.

\section{Plasminogen activators in physiology and pathology}

In addition to their established role in fibrinolysis, PAs might catalyze localized pericellular proteolysis in a very wide spectrum of physiological and pathological situations. A striking illustration of this is provided by a histological assay that reveals PA activity in sections of mouse embryos (Fig. 2). A number of tissues, in particular kidney, skin, intracranial structures, and lung, express PA activity, in a pattern which changes with the developmental stage. Whereas recent in vivo experiments have confirmed that PAs are synthesized and secreted during cell migration and tissue remodeling, other observations have demonstrated that PAs are also expressed by cells that are not involved in such processes. PAs may thus fulfill a larger spectrum of related functions than had previously been suspected.

PAS AND ECM TURNOVER DURING CELL MIGRATION AND TISSUE REMODELING

Embryonic development. The expression of PAs by invasive embryonic cells in vivo has been best documented in tropho-
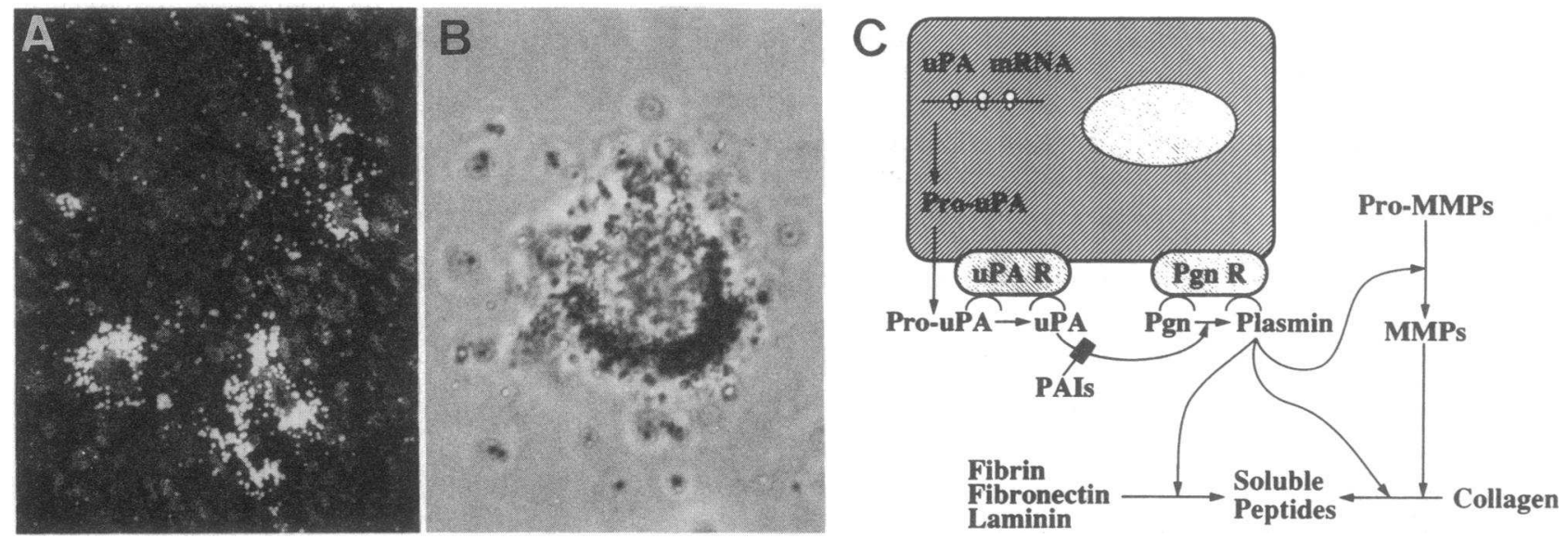

Figure 1. uPA in cell migration. $(A)$ In situ hybridization with a ${ }^{3} \mathrm{H}$-labeled cRNA probe reveals uPA mRNA in invasive trophoblasts migrating from a 6.5-d-old mouse embryo (top) into the surrounding uterine stroma. See reference 42 for experimental details. Silver grains appear as white spots in this dark-field micrograph (magnification, 800). (B) Autoradiographic detection of receptor-bound ${ }^{125}$ I-uPA at the surface of a human monocyte in a chemotactic gradient. The source of the gradient is at the bottom of the photograph. See reference 18 for experimental details. Silver grains appear as black spots in this light-field micrograph, and reveal that the uPA receptor is concentrated at the leading edge of the cell (magnification, 1,400). (C) Schematic representation of the uPA-plasmin system at the surface of receptor-bearing cells. MMPs, matrix metalloproteases; Pgn, plasminogen; $R$, receptors. 
$16 d$
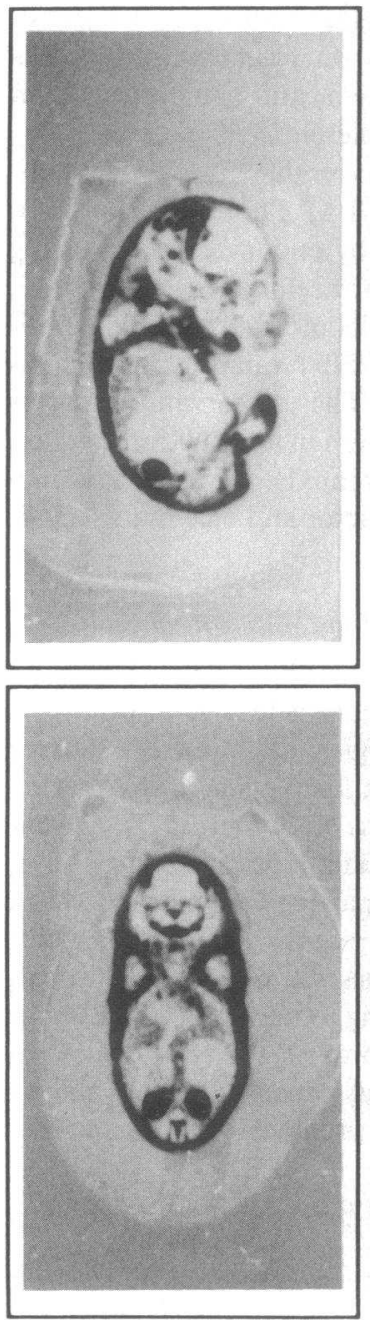

$18 d$
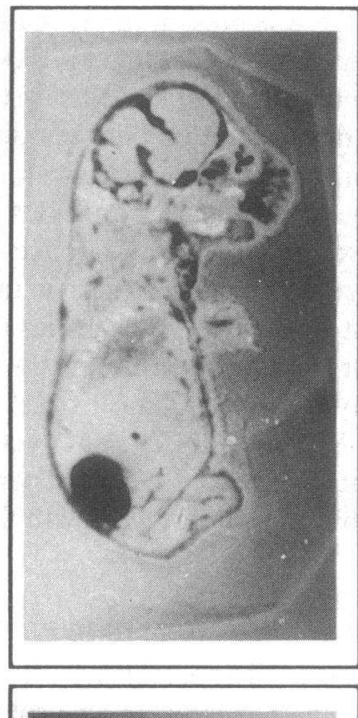

$19 d$
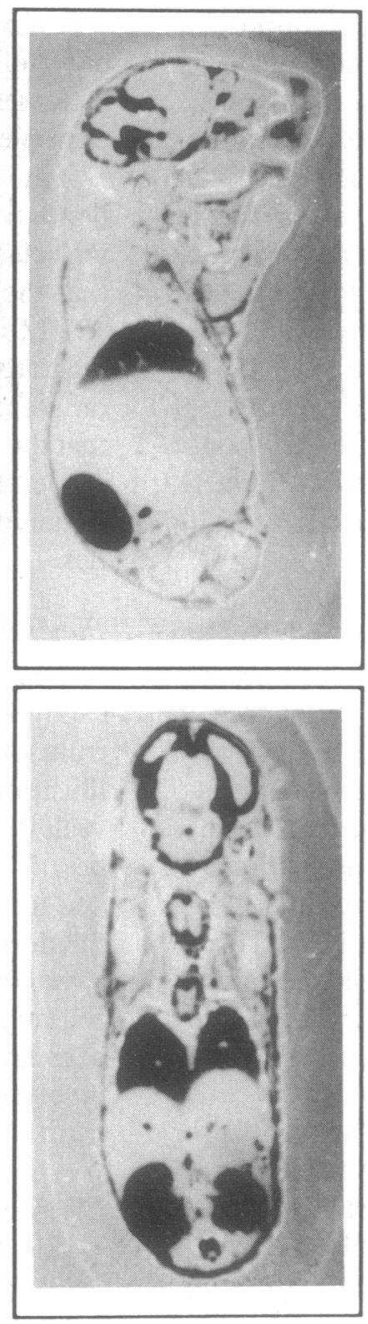

Figure 2. Visualization of PA enzymatic activities on tissue sections of murine embryos. Histological zymographies were performed as described (49). Sagittal (top) and frontal (bottom) cryostat tissue sections of 16-, 18-, and 19-d-old murine embryos were overlayed with a solution containing agar, plasminogen, and casein. Slides were incubated at $37^{\circ} \mathrm{C}$ for $3 \mathrm{~h}$. PAs diffuse from the tissues into the overlay, where they activate plasminogen to plasmin, which in turn lyses the insoluble casein. No lysis is observed in the absence of plasminogen in the overlay (not shown). Photographs were taken using dark-ground illumination, and caseinolytic areas appear black. Note PA enzymatic activity in kidneys, skin, lungs, and intracranial structures (magnification, 2.2). blast cells (42), which produce uPA in a temporal pattern compatible with its involvement in the endometrial disruption accompanying both implantation and early growth of the embryo. Similarly, other migrating embryonic cells, such as hemopoietic cells colonizing the bursa of Fabricius (43); neural crest cells, and cerebellar granular neurons, have been found to produce PAs (44).

Ovulation. The production of PAs by rodent ovaries correlates with ovulation. The participation of the enzymes in follicular rupture has received strong experimental support: both anti-tPA antibodies and $\alpha 2$-antiplasmin can block ovulation (45). The regulated expression of tPA in maturing rodent oocytes has led to the suggestion that it might participate in oocyte maturation and fertilization (46).

Inflammation, wound healing, and angiogenesis. Monocytes/macrophages and PMNs produce uPA, suggesting that it plays a role in the migration of inflammatory cells to the sites of inflammation and in the extensive extracellular remodeling that follows tissue injury. In addition, other cell types involved in inflammatory processes, such as keratinocytes in wound reepithelialization and endothelial cells in angiogenesis, also produce uPA. The angiogenic activity of endothelial cells reflects the balance of PAs and PAIs, as illustrated by the behavior of hemangiomas, in which a shift of the balance towards proteolysis results in abnormal vessel formation (47).

Neoplasia. A large body of evidence implicates uPA in the invasive properties of malignant cells (1). The most direct comes from studies showing that inhibitory anti-uPA antibodies interfere with metastasis of tumor cells in chick embryos. In this model, cell surface receptor-bound uPA is required for one specific stage in metastasis, i.e., stromal invasion (35). In vivo, animal and human tumors often contain high levels of uPA and, in a number of cases, metastatic propensity correlates with the levels of enzyme production: for instance, uPA is abundant in squamous but not in basal cell carcinomas, the former having a higher invasive and metastatic potential (48).

\section{PAS AND THE MAINTENANCE OF FLUIDITY IN TUBULAR STRUCTURES}

Endothelial cells produce tPA; the enzyme, which may remain bound to the cells and/or be released into the blood, is thought to prevent inappropriate clot formation. Recently, uPA and tPA synthesis has been demonstrated in various epithelial cells lining tubular structures, a situation reminiscent of the function of TPA in the vascular bed. In the murine kidney, both PAs are secreted into urine by epithelial cells lining distinct seg- 
ments of urinary tubules (49). Similarly, epithelial cells in the mammary gland, the vas deferens and the seminal vesicle produce and secrete uPA $(32,39)$. These cumulated observations support a role for PAs in the maintenance of patency and fluidity in tubular structures.

PAS AND THE BIOLOGY OF GROWTH FACTORS, HORMONES, AND NEUROPEPTIDES

PAs have been detected in the adult central nervous system (44), as well as in a majority of endocrine glands. Because ECM turnover is probably not a very active process in such tissues, other functions for PA-catalyzed extracellular proteolysis should be envisioned. This has led to the suggestion that PAs might participate in prohormone processing; recent data, which have tentatively identified intracellular processing proteases, do not support this hypothesis. However, the concept of proteolytic activation of hormones and growth factors should be revisited in the light of recent studies: plasmin can activate the latent form of TGF $\beta$ and release bFGF-glycosaminoglycan complexes from the matrix and the cell surface (11), whereas PAs might cause posttranslational processing of hepatocyte growth factor, which has extensive homology with plasminogen. In addition, proteolytic inactivation of growth factors could involve the PA/plasmin system. Modulation of expression of receptors for growth factors, hormones, and neurotransmitters may also be achieved by PA-catalyzed proteolysis, as initially suggested for the EGF receptor (50). Finally, it is conceivable that PAs and PAIs could play a part in controlling the plasticity of synaptic structures.

In conclusion, the PA/plasmin system is part of a cohort of enzymatic pathways that catalyze extracellular proteolysis. We now know that it is expressed in a remarkably broad spectrum of biological situations, indicating the dynamic nature of the interaction of most cells with their environment. To elucidate the functions of PA-catalyzed proteolysis, we need to develop new tools: these may come from the identification of selective and pharmacologically useful inhibitors, or from the genetic approach of transgenic animals. Meeting this challenge will teach us much about the ecology of cells in the organism.

\section{Acknowledgments}

We thank our colleagues Drs. A. Wohlwend, J. Huarte, and M. Pepper for their essential contributions to many aspects of our work, and Mr. J.-P. Gerber for photographic work. The seminal and provocative influence of Dr. Ed Reich on all facets of plasminogen activation is acknowledged.

The work from our laboratories has been funded by the Fonds National Suisse de la Recherche Scientifique, the Ligue Genevoise Contre le Cancer, the Sir Jules Thorn Charitable Overseas Trust, and the Commission Fédérale des Maladies Rhumatismales.

\section{References}

1. Dano, K., P. A. Andreasen, J. Grondahl-Hansen, P. Kristensen, L. S. Nielsen, and L. Skriver. 1985. Plasminogen activators, tissue degradation, and cancer. Adv. Cancer Res. 44:139-266.

2. Petersen, L. C., L. R. Lund, L. S. Nielsen, K. Dano, and L. Skriver. 1988. One-chain urokinase-type plasminogen activator from human sarcoma cells is a proenzyme with little or no intrinsic activity. J. Biol. Chem. 263:11189-11195.

3. Kobayashi, H., M. Schmitt, L. Goretzki, N. Chucholowski, J. Calvete, M Kramer, W. A. Günzler, F. Jänicke, and H. Graeff. 1991. Cathepsin B efficiently activates the soluble and the tumor cell receptor-bound form of the proenzyme urokinase-type plasminogen activator (pro-uPA). J. Biol. Chem. 266:5147-5152.
4. Vassalli, J.-D., D. Baccino, and D. Belin. 1985. A cellular binding site for the $M_{\mathrm{r}} 55,000$ form of the human plasminogen activator, urokinase. J. Cell Biol. 100:86-92.

5. Blasi, F., N. Behrendt, M. V. Cubellis, V. Ellis, L. R. Lund, M. T. Masucci, L. B. Moller, D. P. Olson, N. Pedersen, M. Ploug, E. Ronne, and K. Dano. 1990. The urokinase receptor and regulation of cell surface plasminogen activation. Cell Differ. Dev. 32:247-254.

6. Gething, M. J., B. Adler, J. A. Boose, R. D. Gerard, E. L. Madison, D. McGookey, R. S. Meidell, L. M. Roman, and J. Sambrook. 1988. Variants of human tissue-type plasminogen activator that lack specific structural domains of the heavy chain. EMBO (Eur. Mol. Biol. Organ.) J. 7:2731-2740.

7. Andrade-Gordon, P., and S. Strickland. 1986. Interaction of heparin with plasminogen activators and plasminogen: effects on the activation of plasminogen. Biochemistry. 25:4033-4040.

8. Quigley, J. P., M. B. Berkenpas, R. T. Aimes, and J. M. Chen. 1990. Serine protease and metalloprotease cascade systems involved in pericellular proteolysis. Cell Differ. Dev. 32:263-276.

9. Plow, E. F., and L. A. Miles. 1990. Plasminogen receptors in the mediation of pericellular proteolysis. Cell Differ. Dev. 32:293-298.

10. He, C. S., S. M. Wilhelm, A. P. Pentland, B. L. Marmer, G. A. Grant, A. Z. Eisen, and G. I. Goldberg. 1989. Tissue cooperation in a proteolytic cascade activating human interstitial collagenase. Proc. Natl. Acad. Sci. USA. 86:26322636.

11. Rifkin, D. B., D. Moscatelli, J. Bizik, N. Quarto, F. Blei, P. Dennis, R. Flaumenhaft, and P. Mignatti. 1990. Growth factor control of extracellular proteolysis. Cell Differ. Dev. 32:313-318.

12. Andreasen, P. A., B. Georg, L. R. Lund, A. Riccio, and S. N. Stacey. 1990 Plasminogen activator inhibitors: hormonally regulated serpins. Mol, Cell. Endocrinol. 68:1-19.

13. Seiffert, D., J. Mimuro, R. R. Schleef, and D. J. Loskutoff. 1990. Interactions between type 1 plasminogen activator inhibitor, extracellular matrix and vitronectin. Cell Differ. Dev. 32:287-292.

14. Ehrlich, H. J., J. Keijer, T. Preissner, R. K. Gebbink, and H. Pannekoek 1991. Functional interaction of plasminogen activator inhibitor type 1 (PAI-1) and heparin. Biochemistry. 30:1021-1028.

15. Belin, D., A. Wohlwend, W.-D. Schleuning, E. K. O. Kruithof, and J.-D. Vassalli. 1989. Facultative polypeptide translocation allows a single mRNA to encode the secreted and cytosolic forms of plasminogen activators inhibitor 2 . EMBO (Eur. Mol. Biol. Organ.) J. 8:3287-3294.

16. Longstaff, C., and P. J. Gaffney. 1991. Serpin-serine protease binding kinetics: alpha 2-antiplasmin as a model inhibitor. Biochemistry. 30:979-986.

17. Ploug, M., E. Ronne, N. Behrendt, A. L. Jensen, F. Blasi, and K. Dano 1991. Cellular receptor for urokinase plasminogen activator. Carboxyl-terminal processing and membrane anchoring by glycosyl-phosphatidylinositol. J. Biol. Chem. 266:1926-1933.

18. Estreicher, A., J. Mühlhauser, J.-L. Carpentier, L. Orci, and J.-D. Vassalli. 1990. The receptor for urokinase type plasminogen activator polarizes expression of the protease to the leading edge of migrating monocytes and promotes degradation of enzyme inhibitor complexes. J. Cell Biol. 111:783-792.

19. Ellis, V., T.-C. Wun, N. Behrendt, E. Ronne, and K. Dano. 1990. Inhibition of receptor-bound urokinase by plasminogen-activator inhibitors. J. Biol. Chem. 265:9904-9908.

20. Rijken, D. C., M. Otter, J. Kuiper, and T. J. van Berkel. 1990. Receptormediated endocytosis of tissue-type plasminogen activator (t-PA) by liver cells. Thromb. Res. 10:63-71.

21. Hajjar, K. A., and N. M. Hamel. 1990. Identification and characterization of human endothelial cell membrane binding sites for tissue plasminogen activator and urokinase. J. Biol. Chem. 265:2908-2916.

22. Verrall, S., and N. W. Seeds. 1989. Characterization of ${ }^{125}$ I-tissue plasminogen activator binding to cerebellar granule neurons. J. Cell Biol. 109:265-271.

23. Miles, L. A., C. M. Dahlberg, J. Plescia, J. Felez, K. Kato, and F. Plow. 1991. Role of cell-surface lysines in plasminogen binding to cells: identification of alpha-enolase as a candidate plasminogen receptor. Biochemistry. 30:1682-1691.

24. Rorth, P., C. Nerlov, F. Blasi, and M. Johnsen. 1990. Transcription factor PEA3 participates in the induction of urokinase plasminogen activator transcription in murine keratinocytes stimulated with epidermal growth factor or phorbolester. Nucleic Acids Res. 18:5009-5017.

25. Medcalf, R. L., M. Ruegg, and W.-D. Schleuning. 1990. A DNA motif related to the CAMP-responsive element and an exon-located activator protein-2 binding site in the human tissue-type plasminogen activator gene promoter cooperate in basal expression and convey activation by phorbol ester and cAMP. $J$. Biol. Chem. 265:14618-14626.

26. Von der Ahe, D., D. Pearson, and Y. Nagamine. 1990. Macromolecular interaction on a cAMP responsive region in the urokinase-type plasminogen activator gene: a role of protein phosphorylation. Nucleic Acids Res. 18:19911999.

27. Huarte, J., D. Belin, A. Vassalli, S. Strickland, and J.-D. Vassalli. 1987. Meiotic maturation of mouse oocytes triggers the translation and polyadenylation of dormant tissue-type plasminogen activator mRNA. Genes \& Dev. 1:12011211 . 
28. Collart, M. A., D. Belin, J.-D. Vassalli, and P. Vassalli. 1987. Modulations of functional activity in differentiated macrophages are accompanied by early and transient increase or decrease in c-fos gene transcription. J. Immunol. 139:949-955.

29. Pepper, M. S., D. Belin, R. Montesano, L. Orci, and J.-D. Vassalli. 1990. Transforming growth factor-beta 1 modulates basic fibroblast growth factor-induced proteolytic and angiogenic properties of endothelial cells in vitro. J. Cell Biol. 111:743-755.

30. Pepper, M. S., R. Montesano, J.-D. Vassalli, and L. Orci. 1991. Chondrocytes inhibit endothelial sprout formation in vitro: evidence for involvement of a transforming growth factor-beta. J. Cell. Physiol. 146:170-179.

31. Pepper, M. S., R. Montesano, L. Orci, and J.-D. Vassalli. 1991. Plasminogen activator inhibitor- 1 is induced in microvascular endothelial cells by a chondrocyte-derived transforming growth factor-beta. Biochem. Biophys. Res. Commun. 176:633-638.

32. Larsson, L. I., L. Skriver, L. S. Nielsen, J. Grondahl-Hansen, P. Kristensen, and K. Dano. 1984. Distribution of urokinase-type plasminogen activator immunoreactivity in the mouse. J. Cell Biol. 98:894-903.

33. Heiple, J. M., and L. Ossowski. 1986. Human neutrophil plasminogen activator is localized in specific granules and is translocated to the cell surface by exocytosis. J. Exp. Med. 164:826-840.

34. Van Hinsbergh, V. W. M., E. A. Van den Berg, W. Fiers, and G. Dooijewaard. 1990. Tumor necrosis factor induces the production of urokinase-type plasminogen activator by human endothelial cells. Blood. 75:1991-1998.

35. Ossowski, L. 1988. In vivo invasion of modified chorioallantoic membrane by tumor cells: the role of cell surface-bound urokinase. J. Cell Biol. 107:2437-2445.

36. Estreicher, A., A. Wohlwend, D. Belin, W.-D. Schleuning, and J.-D. Vassalli. 1989. Characterization of the cellular binding sites for the urokinase-type plasminogen activator. J. Biol. Chem. 264:1180-1189.

37. Vaheri, A., R. W. Stephens, E.-M. Salonen, J. Pollanen, and H. Tapiovaara. 1990. Plasminogen activation at the cell surface-matrix interface. Cell. Differ. Dev. 32:255-262.

38. Ellis, V., M. F. Scully, and V. V. Kakkar. 1989. Plasminogen activation initiated by single-chain urokinase-type plasminogen activator. Potentiation by U937 monocytes. J. Biol. Chem. 264:2185-2188.
39. Huarte, J., D. Belin, D. Bosco, A.-P. Sappino, and J.-D. Vassalli. 1987 Plasminogen activator and mouse spermatozoa: urokinase synthesis in the male genital tract and binding of the enzyme to the sperm cell surface. J. Cell Biol. 104:1281-1289.

40. Pyke, C., P. Kristensen, E. Ralfkiaer, J. Grondahl-Hansen, J. Eriksen, F. Blasi, and K. Dano. 1991. Urokinase-type plasminogen activator is expressed in stromal cells and its receptor in cancer cells at invasive foci in human colon adenocarcinomas. Am. J. Pathol. 138:1059-1067.

41. Nusrat, A. R., and H. A. Chapman. 1991. An autocrine role for urokinase in phorbol ester-mediated differentiation of myeloid cell lines. J. Clin. Invest. 87:1091-1097.

42. Sappino, A.-P., J. Huarte, D. Belin, and J.-D. Vassalli. 1989. Plasminogen activators in tissue remodeling and invasion: mRNA localization in mouse ovaries and implanting embryos. J. Cell Biol. 109:2471-2479.

43. Valinsky, J. E., E. Reich, and N. Le Douarin. 1981. Plasminogen activator in the bursa of Fabricius: correlations with morphogenetic remodeling and cell migrations. Cell. 25:471-476.

44. Festoff, B. W., editor. 1990. Serine proteases and their serpin inhibitors in the nervous system. In Regulation in Development and in Degenerative and Malignant disease. Plenum Publishing Corp., New York.

45. Tsafriri, A., T. A. Bicsak, S. B. Cajander, T. Ny, and A. J. Hsueh. 1989. Suppression of ovulation rate by antibodies to tissue-type plasminogen activator and alpha 2-antiplasmin. Endocrinology. 124:415-421.

46. Huarte, J., D. Belin, and J.-D. Vassalli. 1985. Plasminogen activator in mouse and rat oocytes: induction during meiotic maturation. Cell. 43:551-558.

47. Pepper, M. S., and R. Montesano. 1990. Proteolytic balance and capillary morphogenesis. Cell Differ. Dev. 32:319-328.

48. Sappino, A.-P., D. Belin, J. Huarte, S. Hirschel-Scholz, J. H. Saurat, and J.-D. Vassalli. 1991. Differential protease expression by cutaneous squamous and basal cell carcinomas. J. Clin. Invest. 88:1074-1080.

49. Sappino, A.-P., J. Huarte, J.-D. Vassalli, and D. Belin. 1991. Sites of synthesis of urokinase and tissue-type plasminogen activators in the murine kidney. J. Clin. Invest. 87:962-970.

50. Gross, J. L., M. N. Krupp, D. B. Rifkin, and M. D. Lane. 1983. Downregulation of epidermal growth factor receptor correlates with plasminogen activator activity in human A431 epidermoid carcinoma cells. Proc. Natl. Acad. Sci. USA. 80:2276-2280 